\title{
Association of Perceived Environment and Physical Activity in Older Adults After the Great East Japan Earthquake
}

\author{
Nobuaki Moriyama, Hajime Iwasa, and Seiji Yasumura
}

\begin{abstract}
The aim of this study was to examine the association between perceived environment and physical activity among older adults in Fukushima Prefecture after the 2011 Great East Japan Earthquake and the impact of evacuation. Questionnaires were distributed to individuals aged 65 years and older from October to November 2018. Perceived environment was assessed using a five-item questionnaire on home fitness equipment, access to facilities, neighborhood safety, enjoyable scenery, and frequency of observing others exercising. Physical activity, assessed via the Physical Activity Questionnaire for Elderly Japanese, was segregated into levels based on the median score. Data from 249 participants $(74.2 \pm 6.9$ years $)$ were analyzed. A logistic regression analysis found that the unenjoyable Scenery $\times$ Residing in restoration public housing interaction $($ odds ratio $=3.87$, $95 \%$ confidence interval $=[1.20,12.46])$ was significant. The association between enjoyable scenery and physical activity varied according to whether the participants had experienced evacuation or not.
\end{abstract}

Keywords: disaster, evacuation, older people

Physical activity includes "any bodily movement produced by the skeletal muscles that results in energy expenditure" (Caspersen, Powell, \& Christenson, 1985). Globally, physical inactivity has been identified as the fourth leading risk factor for mortality, contributing to $6 \%$ of deaths worldwide (World Health Organization, 2009), and it is also a major cause of noncommunicable diseases (Lee et al., 2012). Physical activity has various health benefits for older adults, including improved physical and mental function (McPhee et al., 2016). In the Japanese context, the Ministry of Health, Labour and Welfare published recommendations for physical activity in March 2013 (Ministry of Health, Labour and Welfare, 2013; Murakami, Tripette, Kawakami, \& Miyachi, 2015).

The Great East Japan Earthquake (GEJE) of March 2011 induced the Fukushima Daiichi nuclear disaster, where radioactive material emitted from a damaged power plant led to a variety of social and health issues (Hasegawa et al., 2015; Ohira et al., 2017; Yasumura, Goto, Yamazaki, \& Reich, 2013). The secondary impacts, which were caused by the disaster itself rather than radiation exposure, included lifestyle changes and restricted access to medical services (Ochi et al., 2016), resulting in residents' vulnerability to chronic diseases.

In recent years, ecological models providing a useful framework for conceptualizing multiple levels of health behavior determinants have been developed (Glanz, Rimer, \& Viswanath, 2015). Sallis et al. (2006) suggested that an individual's perceptions of their

(C) 2021 The Authors. Published by Human Kinetics, Inc. This is an Open Access article distributed under the terms of the Creative Commons Attribution-NonCommercial-NoDerivatives 4.0 International License, CC BY-NC-ND 4.0, which permits the copy and redistribution in any medium or format, provided it is not used for commercial purposes, no modifications are made, appropriate credit is given, and a link to the license is provided. See http://creativecommons.org/licenses/ by-nc-nd/4.0. This license does not cover any third-party material that may appear with permission in the article. For commercial use, permission should be requested from Human Kinetics, Inc., through the Copyright Clearance Center (http://www. copyright.com).

The authors are with the Department of Public Health, Fukushima Medical University School of Medicine, Fukushima Medical University, Fukushima, Japan. Moriyama (moriyama@fmu.ac.jp) is corresponding author. environment, coupled with objective environmental aspects, influence active living behavior. A study reported a relationship between various types of perceived environments and physical activity (Shibata, Oka, Harada, Nakamura, \& Muraoka, 2009), while others reported low physical activity among temporary housing residents after the GEJE (Murakami et al., 2014) and among locals following a major earthquake in Italy in 2009 (Minardi et al., 2016). Thus, situations developing after a disaster may affect local citizens' active lifestyles. Furthermore, evacuation and relocation cause dramatic lifestyle changes and are reported to be associated with low physical activity (Moriyama, Urabe, Onoda, Maeda, \& Oikawa, 2017).

Owing to the Fukushima nuclear accident, many locals experienced multiple evacuations (Hasegawa et al., 2015), with some living in a housing complex, restoration public housing (RPH), built by the Prefectural Government of Fukushima for those who had not yet decided where to live. Although rebuilding disaster-affected areas can take several years, improving individuals' perceptions of their surrounding environments could be an effective intervention to improve quality of life. Thus, in this study, we focused on the potential association between perceived environment and physical activity levels in older adults and further examined the correlations between different types of perceived environments and physical activity. In addition, we examined whether the association between perceived environment and physical activity levels could vary according to the experience of evacuation.

\section{Materials and Methods}

\section{Design}

This study employed a cross-sectional design to analyze data obtained from the survey by Moriyama et al. (2019) for the purpose of examining the association between social capital and subjective well-being of RPH residents.

\section{Participants, Setting, and Sampling}

The survey targeted residents of Fukushima Prefecture aged 65 years or older. Study sites included Fukushima, Koriyama, and 
Iwaki, three of the larger cities in Fukushima Prefecture, with populations ranging from 290,000 to 340,000 . Using two-stage stratified random sampling, we sent questionnaires to 600 households in RPH (200 in each city) and to 300 in other types of housing (100 in each city). This anonymous self-report survey was conducted from October 30 to November 27, 2018. To select nonRPH participants, we used the Basic Resident Register, which stores proof of residence at the municipality office. We could not use the same register to sample RPH residents because many of them had maintained their resident registration in their original municipalities. Therefore, to choose the RPH sample, we randomly selected complex housing units and posted the questionnaire to $600 \mathrm{RPH}$ households, which we expected to include $\sim 300$ residents aged 65 years or older.

\section{Measured Items}

Dependent variable. Physical activity level was measured with the Physical Activity Questionnaire for Elderly Japanese (PAQEJ), the reliability and validity of which have been proven by the developers (Yasunaga et al., 2007). The PAQ-EJ is a self-administered questionnaire that explores the frequency and duration of involvement in seven categories of physical activity during a typical week (Table 1): transportation, light exercise/sports, moderate or somewhat strenuous exercise/sports, light housework, resistance exercise/sports, moderate or somewhat heavy housework, and labor. Respondents indicate their frequency of engagement in each category of physical activity in a given week and the time allocated to a given activity during a typical day. In this study,

\section{Table 1 Physical Activity Questionnaire for Elderly Japanese}

\begin{tabular}{ll}
\hline Categories & Questions \\
\hline Transportation & $\begin{array}{l}\text { Over } 7 \text { typical days, how often did you take a walk or ride a bicycle on errands, such as going to or from a store or } \\
\text { taking children to school? }\end{array}$ \\
Over 7 typical days, how often did you participate in light sport and recreational activities, such as leisurely \\
walking for exercise or pleasure, stretching, or flexibility exercises, golf, gateball, etc.? \\
Moderate or somewhat strenuous \\
Over 7 typical days, how often did you participate in moderate or somewhat strenuous sport and recreational \\
activities, such as walking fast or briskly for exercise, dance, tennis, jogging, swimming, skiing, etc.? \\
Resistance exercise/sports & $\begin{array}{l}\text { Over } 7 \text { typical days, how often did you perform any exercises specifically to increase muscle strength and } \\
\text { endurance, such as lifting handheld weights, using weight machines or elastic bands, etc.? }\end{array}$ \\
Light housework & $\begin{array}{l}\text { Over } 7 \text { typical days, how often did you carry out any light household activities, such as dusting, sweeping or } \\
\text { vacuuming, cooking, washing dishes, watering plants, etc.? } \\
\text { Over } 7 \text { typical days, how often did you carry out any moderate or somewhat heavy household activities, such as } \\
\text { woderate or somewhat heavy }\end{array}$ \\
housework & $\begin{array}{l}\text { carpentry or repairs like painting wallpapering, etc.? } \\
\text { Over } 7 \text { typical days, how often did you do any laborious activities, such as agricultural spading, raking, etc.? }\end{array}$ \\
Labor &
\end{tabular}

\begin{tabular}{|c|c|}
\hline Items for calculating physical activity of each category & Code \\
\hline \multicolumn{2}{|l|}{ Weekly frequency } \\
\hline Never (0 days) & 0 \\
\hline Seldom ( 1 or 2 days) & 1.5 \\
\hline Sometimes ( 3 or 4 days) & 3.5 \\
\hline Often (5-7 days) & 6 \\
\hline \multicolumn{2}{|l|}{ Time per day } \\
\hline Less than $30 \mathrm{~min}$ & 0.25 \\
\hline Less than $1 \mathrm{hr}$ & 0.5 \\
\hline $30 \mathrm{~min}$, but less than $1 \mathrm{hr}$ & 0.75 \\
\hline $1 \mathrm{hr}$, but less than $2 \mathrm{hr}$ & 1.5 \\
\hline $2 \mathrm{hr}$ or more & 2.5 \\
\hline $2 \mathrm{hr}$, but less than $4 \mathrm{hr}$ & 3 \\
\hline $4 \mathrm{hr}$ or more & 5 \\
\hline \multicolumn{2}{|l|}{ Intensity weight assigned to physical activity } \\
\hline Transportation & 2.8 \\
\hline Light exercise/sports & 3.0 \\
\hline Moderate or somewhat strenuous exercise/sports & 4.3 \\
\hline Resistance exercise/sports & 3.0 \\
\hline Light housework & 2.0 \\
\hline Moderate or somewhat heavy housework & 2.5 \\
\hline Labor & 2.8 \\
\hline
\end{tabular}

Note. Physical Activity Questionnaire for Elderly Japanese score (metabolic equivalent of task hours/week) for each category: Number of Days $\times$ Time $\times$ Intensity weight. Total Physical Activity Questionnaire for Elderly Japanese score: Sum of the seven categories. 
categorical data were subsequently converted to arbitrary scores, using midpoints for the stated frequency and duration of potential responses. Based on data reported by Stewart et al. (2001), to convert these arbitrary PAQ-EJ scores to metabolic equivalents of task (MET, hours/week), an intensity weight was assigned to each physical activity category.

Independent variables. Perceived environment factors were the independent variables, where the perceived neighborhood environments for physical activity were considered representative of environmental factors (Oka, Togo, \& Aoyagi, 2004; Sallis et al., 2006). The five items in the questionnaire included: (a) I possess home fitness equipment (shoes, pedometer, dumbbells, etc.); (b) my neighborhood provides facilities (walking trail, park, fitness club, etc.) for engaging in physical activity; (c) My neighborhood provides a safe and well-maintained environment (adequate lighting and sidewalks, light traffic volume, etc.) for being physically active; (d) I have access to enjoyable scenery when engaging in physical activity; and (e) I frequently observe other people exercising. Possible responses were yes ( 1 point) or no ( 0 points). The scores were summed (range: $0-5$, Cronbach's $\alpha=.711$ ) and analyzed as overall perceived environment.

Covariates. The following covariates were chosen based on previous research on determinants of physical activity in adults (Sallis \& Owen, 1999).

Social support. Four dimensions of social support were assessed with the 2-Way Social Support Scale (ShakespeareFinch \& Obst, 2011). The evaluation included the following four questions: "Do you listen to someone else's concerns and complaints?" (providing emotional support); "Do you take care of someone who is sick?" (providing instrumental support); "Do you have someone who listens to your concerns and complaints?" (receiving emotional support); and "Do you have someone who takes care of you when you are sick?" (receiving instrumental support). Respondents were instructed to select one or multiple responses from the following: "spouse," "children within the household," "children and other relatives outside the household," "neighbors," "friends," "others," and "none." Responses were dichotomized into presence or absence of each type of social support based on whether participants responded "none" or other than "none." Finally, participants were segregated on the basis of the presence or absence of all four dimensions of social support (Sasaki et al., 2019).

Social participation. Participants were asked whether they belonged to the following: "territorial organizations," "exercise or sports groups," "volunteer activity groups," "hobby and lifelong study groups," "religious groups," or "political organizations." Responses were categorized according to the presence or absence of participation in at least one of the six listed groups.

Health-related quality of life. The Medical Outcomes Study Short-Form 12 was administered to measure health-related quality of life (Hurst, Ruta, \& Kind, 1998); it has been found to have a positive relationship with regular exercise in adults (Chang et al., 2019). The tool's mental component summary scores were included in the analysis.

Functional status. We used the Tokyo Metropolitan Institute of Gerontology Index of Competence (Koyano, Shibata, Nakazato, Haga, \& Suyama, 1991), with "yes" responses (able to do) scored 1 and "no" (unable) scored 0 . The total score-the sum of the scores of 13 items — was dichotomized into "high" (13 points) or "low" ( $\leq 12$ points; Fujiwara, Kondo, Shirai, Suzuki, \& Kawachi, 2014).
Sociodemographic information. Information including age, gender, household structure (living alone/living with others), and history of heart disease (presence/absence) was also obtained.

\section{Statistical Methods}

The physical activity score distribution was checked based on whether the variable was to be treated as continuous or dichotomized. Logistic regression analysis was used to examine the association between physical activity and perceived environment, with physical activity as the dependent variable and each type of perceived environment, and the total score for each type of perceived environment, as key independent variables. Age, gender, type of residence, and an interaction of residence type and perceived environment were included as covariates in Model 1, and other variables found to be associated with physical activity in the univariate analysis were gradually added in the advanced model. As a secondary analysis, stratified analysis according to residence type (RPH or non-RPH) was performed on the same model. The level of significance for all analyses was set at $p<.05$. All data were analyzed using HAD software (Shimizu, 2016).

\section{Ethical Considerations}

The study was approved by the ethics committee of Fukushima Medical University (approval number: 30104) and conducted in accordance with the ethical principles of the Declaration of Helsinki. We attached a letter with the questionnaire stating that we considered submitting a returned questionnaire to be indicative of agreement with the study objectives and voluntary participation; thus, written informed consent was not necessary. The reporting adheres to STROBE recommendations (von Elm et al., 2007).

\section{Results}

In total, 311 older adults (122 from the RPH group, 189 from the non$\mathrm{RPH}$ group) responded to the questionnaire. The response rate was $\sim 40 \%$ (exact value not available) in the RPH group and $63 \%$ in the non-RPH group. Excluding questionnaires with incomplete responses, the data of 249 participants (mean age $=73.8 \pm 6.9$ years, 130 females) were included in the analyses. The valid response rate was $-30 \%$ in the RPH group and $52.3 \%$ in the non-RPH group.

The median physical activity level of all participants was 43.05 MET hr/week (interquartile range =19.16-85.05; Table 2). The kurtosis and skewness of the distribution of the physical activity score was 4.056 and 1.719 , respectively. Since the distribution was not normal, participants were divided into a high and low physical activity group according to the median.

Univariate analysis showed that female gender, lack of social participation, lower health-related quality of life, lower functional status, lack of social support, and residence in RPH were significantly associated with low physical activity, whereas age, history of heart disease, and household structure were not (Table 3). For perceived environment, lacking home fitness equipment was significantly associated with low physical activity (Table 4).

Based on the univariate analysis, social participation and social support were additionally included in Model 2. Mental component summary and Tokyo Metropolitan Institute of Gerontology Index of Competence scores were added in Model 3. The logistic regression analysis showed that the total scores of perceived environment and home fitness equipment (odds ratio $[\mathrm{OR}]=1.83 ; 95 \%$ confidence interval $[\mathrm{CI}]=[1.02,3.28]$ ) were 
Table 2 Physical Activity Scores as Obtained From the Physical Activity Questionnaire for Elderly Japanese

\begin{tabular}{lcc}
\hline Physical activity score & Median & Interquartile range \\
\hline Total & 43.05 & $19.16-85.05$ \\
Transportation & 4.90 & $1.05-14.70$ \\
Light exercise/sports & 6.75 & $2.25-15.75$ \\
Moderate or somewhat strenuous exercise/sports & 0.00 & $0.00-8.60$ \\
Resistance exercise/sports & 0.00 & $0.00-1.13$ \\
Light housework & 6.00 & $3.50-18.00$ \\
Moderate or somewhat heavy housework & 1.88 & $0.00-5.63$ \\
Labor & 0.00 & $0.00-2.10$ \\
\hline
\end{tabular}

Note. Scores were converted to metabolic equivalent of task hours per week.

Table 3 Participant Characteristics by Physical Activity Level

\begin{tabular}{|c|c|c|c|}
\hline & High physical activity, $n(\%)$ & Low physical activity, $\boldsymbol{n}(\%)$ & \\
\hline Items & $n=125$ & $n=124$ & $p$ value \\
\hline Age, mean $(S D)$ & $73.8(6.9)$ & $74.6(6.9)$ & .360 \\
\hline \multicolumn{4}{|l|}{ Gender } \\
\hline Male & $49(39.2)$ & $70(56.5)$ & .006 \\
\hline Female & $76(60.8)$ & $54(43.5)$ & \\
\hline \multicolumn{4}{|l|}{ Residence } \\
\hline $\mathrm{RPH}$ & $39(31.2)$ & $57(46.0)$ & .017 \\
\hline Non-RPH & $86(68.8)$ & $67(54.0)$ & \\
\hline \multicolumn{4}{|l|}{ Social participation } \\
\hline No & $44(35.2)$ & $60(48.4)$ & .035 \\
\hline Yes & $81(64.8)$ & $64(51.6)$ & \\
\hline HRQOL, mean $(S D)$ & $52.5(8.8)$ & $50.1(8.8)$ & .031 \\
\hline \multicolumn{4}{|l|}{ Social support } \\
\hline Yes & $110(88.0)$ & $92(74.2)$ & .005 \\
\hline No & $15(12.0)$ & $32(25.8)$ & \\
\hline \multicolumn{4}{|l|}{ Living alone } \\
\hline Yes & $37(29.6)$ & $38(30.6)$ & .857 \\
\hline No & $88(70.4)$ & $86(69.4)$ & \\
\hline \multicolumn{4}{|c|}{ History of heart disease } \\
\hline Yes & $11(8.8)$ & $19(15.3)$ & .114 \\
\hline No & $114(91.2)$ & $105(84.7)$ & \\
\hline \multicolumn{4}{|l|}{ Functional status } \\
\hline High & $68(54.4)$ & $33(26.6)$ & $<.001$ \\
\hline Low & $57(45.6)$ & $91(73.4)$ & \\
\hline
\end{tabular}

Note. $\mathrm{RPH}=$ restoration public housing; $\mathrm{HRQOL}=$ health-related quality of life.

associated with physical activity in Model 3 (Table 5). An interaction effect of residence and enjoyable scenery on physical activity was also observed in Model $3(\mathrm{OR}=3.87$; 95\% CI = [1.20, 12.46]; Table 5).

The results of stratified logistic regression analysis are presented in Table 6 (RPH group) and Table 7 (non-RPH group). In the RPH group, the association between the total score and physical activity was significant in $\operatorname{Model} 2(\mathrm{OR}=0.72 ; 95 \% \mathrm{CI}=[0.54,0.97])$ and borderline significant in Model $3(\mathrm{OR}=0.75 ; 95 \% \mathrm{CI}=$ $[0.56,1.01]$; Table 6$)$. The association between enjoyable scenery and physical activity was significant in Model $2(\mathrm{OR}=2.58 ; 95 \%$ $\mathrm{CI}=[0.99,6.74])$ and borderline significant in Model $3(\mathrm{OR}=$ $2.30 ; 95 \% \mathrm{CI}=[0.85,6.19]$; Table 6$)$. In the non-RPH group, home fitness equipment was significantly associated with physical activity in Model $3(\mathrm{OR}=2.60 ; 95 \% \mathrm{CI}=[1.14,5.92]$; Table 7).

\section{Discussion}

This study is the first to examine the association between each domain of perceived environment and physical activity among older adults in Fukushima Prefecture after the GEJE and the impact of evacuation. The results suggest that the association of enjoyable scenery with physical activity varied according to the experience of evacuation. In addition, while physical activity was associated with enjoyable scenery in all RPH residents, among non-RPH residents, this association was observed only in those 
Table 4 Perceived Environment by Physical Activity Level

\begin{tabular}{|c|c|c|c|}
\hline & High physical activity, $n(\%)$ & Low physical activity, $n(\%)$ & \\
\hline Perceived environment & $n=125$ & $n=124$ & $p$ value \\
\hline \multicolumn{4}{|l|}{ Home fitness equipment } \\
\hline No & $33(26.4)$ & $57(46.0)$ & .001 \\
\hline Yes & $92(73.6)$ & $67(54.0)$ & \\
\hline \multicolumn{4}{|l|}{ Access to facilities } \\
\hline No & $44(35.2)$ & $53(42.7)$ & .222 \\
\hline Yes & $81(64.8)$ & $71(57.3)$ & \\
\hline \multicolumn{4}{|l|}{ Neighborhood safety } \\
\hline No & $50(40.0)$ & $57(46.0)$ & .342 \\
\hline Yes & $75(60.0)$ & $67(54.0)$ & \\
\hline \multicolumn{4}{|l|}{ Enjoyable scenery } \\
\hline No & $56(44.8)$ & $61(49.2)$ & .487 \\
\hline Yes & $69(55.2)$ & $63(50.8)$ & \\
\hline \multicolumn{4}{|c|}{ Frequency of observing others exercising } \\
\hline No & $53(42.4)$ & $57(46.0)$ & .571 \\
\hline Yes & $72(57.6)$ & $67(54.0)$ & \\
\hline
\end{tabular}

Table 5 ORs of Low Physical Activity Level by Environment $(N=249)$

\begin{tabular}{|c|c|c|c|c|c|c|c|c|c|}
\hline \multirow[b]{2}{*}{ Perceived environment } & \multicolumn{3}{|c|}{ Model 1} & \multicolumn{3}{|c|}{ Model 2} & \multicolumn{3}{|c|}{ Model 3} \\
\hline & OR & $95 \% \mathrm{Cl}$ & $p$ value & OR & $95 \% \mathrm{Cl}$ & $p$ value & OR & $95 \% \mathrm{Cl}$ & $p$ value \\
\hline $\begin{array}{l}\text { Total score for perceived environment } \\
\text { (for 1-point increase) }\end{array}$ & 0.79 & {$[0.66,0.94]$} & .008 & 0.84 & {$[0.70,0.99]$} & .041 & 0.89 & {$[0.75,1.07]$} & .209 \\
\hline Interaction term & 0.73 & {$[0.52,1.02]$} & .062 & 0.77 & {$[0.54,1.09]$} & .140 & 0.77 & {$[0.54,1.08]$} & .129 \\
\hline \multicolumn{10}{|l|}{ Home fitness equipment } \\
\hline Yes & 1.00 & (ref) & .007 & 1.00 & (ref) & .009 & 1.00 & (ref) & .042 \\
\hline No & 2.22 & {$[1.24,3.95]$} & & 2.14 & {$[1.21,3.78]$} & & 1.83 & {$[1.02,3.28]$} & \\
\hline Interaction term & 0.84 & {$[0.27,2.60]$} & .768 & 0.61 & {$[0.18,2.03]$} & .418 & 0.64 & {$[0.19,2.17]$} & .472 \\
\hline \multicolumn{10}{|l|}{ Access to facilities } \\
\hline Yes & 1.00 & (ref) & .142 & 1.00 & (ref) & .343 & 1.00 & (ref) & .586 \\
\hline No & 1.53 & {$[0.87,2.71]$} & & 1.31 & {$[0.75,2.26]$} & & 1.11 & {$[0.63,1.93]$} & \\
\hline Interaction term & 1.63 & {$[0.53,5.01]$} & .396 & 1.30 & {$[0.40,4.17]$} & .660 & 1.40 & {$[0.44,4.44]$} & .444 \\
\hline \multicolumn{10}{|l|}{ Neighborhood safety } \\
\hline Yes & 1.00 & (ref) & .119 & 1.00 & (ref) & .226 & 1.00 & (ref) & .430 \\
\hline No & 1.56 & {$[0.89,2.74]$} & & 1.41 & {$[0.81,2.47]$} & & 1.26 & {$[0.71,2.26]$} & \\
\hline Interaction term & 1.80 & {$[0.60,5.39]$} & .293 & 1.47 & {$[0.48,4.52]$} & .505 & 1.41 & {$[0.45,4.40]$} & .550 \\
\hline \multicolumn{10}{|l|}{ Enjoyable scenery } \\
\hline Yes & 1.00 & (ref) & .105 & 1.00 & (ref) & .459 & 1.00 & (ref) & .861 \\
\hline No & 1.60 & {$[0.91,2.83]$} & & 1.24 & {$[0.71,2.17]$} & & 1.05 & {$[0.59,1.89]$} & \\
\hline Interaction term & 3.85 & {$[1.28,11.62]$} & .017 & 4.01 & {$[1.27,12.71]$} & .018 & 3.87 & {$[1.20,12.46]$} & .023 \\
\hline \multicolumn{10}{|l|}{ Frequency of observing others exercising } \\
\hline Yes & 1.00 & (ref) & .127 & 1.00 & (ref) & .277 & 1.00 & (ref) & .596 \\
\hline No & 1.57 & {$[0.88,2.81]$} & & 1.37 & {$[0.78,2.43]$} & & 1.17 & {$[0.65,2.10]$} & \\
\hline Interaction term & 2.49 & {$[0.83,7.49]$} & .104 & 2.45 & {$[0.78,7.67]$} & .096 & 2.58 & {$[0.81,8.24]$} & .109 \\
\hline
\end{tabular}

Note. Total score for perceived environment: Summed score for each domain of perceived environment including home fitness equipment, access to facilities, neighborhood safety, enjoyable scenery, and frequency of observing others exercising (range: 0-5, higher scores indicating better perceived environment). Model 1: Each perceived environment, residence type, interaction term (RPH $\times$ Poor perceived environment), age, and gender; Model 2: Model $1+$ social participation and social support; and Model 3: Model $2+$ mental component of health-related quality of life and functional status. $\mathrm{OR}=$ odds ratio; $\mathrm{CI}=$ confidence interval; $\mathrm{RPH}=$ restoration public housing. 
Table 6 ORs of Low Physical Activity Level by Environment in RPH Residents (Stratified Analysis; $n=96$ )

\begin{tabular}{|c|c|c|c|c|c|c|c|c|c|}
\hline \multirow[b]{2}{*}{ Perceived environment } & \multicolumn{3}{|c|}{ Model 1} & \multicolumn{3}{|c|}{ Model 2} & \multicolumn{3}{|c|}{ Model 3} \\
\hline & OR & $95 \% \mathrm{Cl}$ & $p$ value & OR & $95 \% \mathrm{Cl}$ & $p$ value & OR & $95 \% \mathrm{Cl}$ & $p$ value \\
\hline $\begin{array}{l}\text { Total score for perceived environment } \\
\text { (for 1-point increase) }\end{array}$ & 0.69 & {$[0.52,0.90]$} & .007 & 0.72 & {$[0.54,0.97]$} & .029 & 0.75 & {$[0.56,1.01]$} & .059 \\
\hline \multicolumn{10}{|l|}{ Home fitness equipment } \\
\hline Yes & 1.00 & (ref) & .079 & 1.00 & (ref) & .167 & 1.00 & (ref) & .297 \\
\hline No & 2.22 & {$[0.91,5.38]$} & & 2.05 & {$[0.74,5.64]$} & & 1.75 & {$[0.61,5.02]$} & \\
\hline \multicolumn{10}{|l|}{ Access to facilities } \\
\hline Yes & 1.00 & (ref) & .125 & 1.00 & (ref) & .280 & 1.00 & (ref) & .401 \\
\hline No & 2.01 & {$[0.82,4.89]$} & & 1.66 & {$[0.66,4.18]$} & & 1.48 & {$[0.59,3.67]$} & \\
\hline \multicolumn{10}{|l|}{ Neighborhood safety } \\
\hline Yes & 1.00 & (ref) & .155 & 1.00 & (ref) & .371 & 1.00 & (ref) & .503 \\
\hline No & 1.87 & {$[0.79,4.41]$} & & 1.49 & {$[0.62,3.60]$} & & 1.37 & {$[0.55,3.44]$} & \\
\hline \multicolumn{10}{|l|}{ Enjoyable scenery } \\
\hline Yes & 1.00 & (ref) & .022 & 1.00 & (ref) & .054 & 1.00 & (ref) & .100 \\
\hline No & 2.98 & {$[1.17,7.58]$} & & 2.58 & {$[0.99,6.74]$} & & 2.30 & {$[0.85,6.19]$} & \\
\hline \multicolumn{10}{|l|}{ Frequency of observing others exercising } \\
\hline Yes & 1.00 & (ref) & .068 & 1.00 & (ref) & .146 & 1.00 & (ref) & .210 \\
\hline No & 2.30 & {$[0.94,5.62]$} & & 1.99 & {$[0.79,5.02]$} & & 1.85 & {$[0.71,4.86]$} & \\
\hline
\end{tabular}

Note. Total score for perceived environment: Summed score for each domain of perceived environment including home fitness equipment, access to facilities, neighborhood safety, enjoyable scenery, and frequency of observing others exercising (range: 0-5, higher scores indicating better perceived environment). Model 1: Each perceived environment, age, and gender; Model 2: Model $1+$ social participation and social support; and Model 3: Model $2+$ mental component of health-related quality of life and functional status. $\mathrm{OR}=$ odds ratio; $\mathrm{CI}=$ confidence interval; $\mathrm{RPH}=$ restoration public housing.

Table 7 ORs of Low Physical Activity Level by Environment in Non-RPH Residents (Stratified Analysis; $n=153$ )

\begin{tabular}{|c|c|c|c|c|c|c|c|c|c|}
\hline \multirow[b]{2}{*}{ Perceived environment } & \multicolumn{3}{|c|}{ Model 1} & \multicolumn{3}{|c|}{ Model 2} & \multicolumn{3}{|c|}{ Model 3} \\
\hline & OR & $95 \% \mathrm{Cl}$ & $p$ value & OR & $95 \% \mathrm{Cl}$ & $p$ value & OR & $95 \% \mathrm{Cl}$ & $p$ value \\
\hline $\begin{array}{l}\text { Total score for perceived environment } \\
\text { (for 1-point increase) }\end{array}$ & 0.91 & {$[0.75,1.12]$} & .382 & 0.90 & {$[0.72,1.11]$} & .316 & 0.96 & {$[0.76,1.20]$} & .721 \\
\hline \multicolumn{10}{|l|}{ Home fitness equipment } \\
\hline Yes & 1.00 & (ref) & .019 & 1.00 & (ref) & .007 & 1.00 & (ref) & .023 \\
\hline No & 2.46 & {$[1.16,5.24]$} & & 3.06 & {$[1.35,6.90]$} & & 2.60 & {$[1.14,5.92]$} & \\
\hline \multicolumn{10}{|l|}{ Access to facilities } \\
\hline Yes & 1.00 & (ref) & .570 & 1.00 & (ref) & .549 & 1.00 & (ref) & .916 \\
\hline No & 1.22 & {$[0.61,2.43]$} & & 1.24 & {$[0.61,2.50]$} & & 1.04 & {$[0.50,2.15]$} & \\
\hline \multicolumn{10}{|l|}{ Neighborhood safety } \\
\hline Yes & 1.00 & (ref) & .541 & 1.00 & (ref) & .334 & 1.00 & (ref) & .539 \\
\hline No & 1.25 & {$[0.61,2.53]$} & & 1.45 & {$[0.68,3.05]$} & & 1.28 & {$[0.59,2.77]$} & \\
\hline \multicolumn{10}{|l|}{ Enjoyable scenery } \\
\hline Yes & 1.00 & (ref) & .529 & 1.00 & (ref) & .325 & 1.00 & (ref) & .190 \\
\hline No & 0.81 & {$[0.41,1.58]$} & & 0.70 & {$[0.35,1.42]$} & & 0.61 & {$[0.29,1.28]$} & \\
\hline \multicolumn{10}{|l|}{ Frequency of observing others exercising } \\
\hline Yes & 1.00 & (ref) & .913 & 1.00 & (ref) & .881 & 1.00 & (ref) & .715 \\
\hline No & 1.04 & {$[0.52,2.10]$} & & 1.06 & {$[0.51,2.19]$} & & 0.87 & {$[0.41,1.85]$} & \\
\hline
\end{tabular}

Note. Total score for perceived environment: Summed score for each domain of perceived environment including home fitness equipment, access to facilities, neighborhood safety, enjoyable scenery, and frequency of observing others exercising (range: $0-5$, higher scores indicating better perceived environment). Model 1: Each perceived environment, age, and gender; Model 2: Model $1+$ social participation and social support; and Model 3: Model $2+$ mental component of health-related quality of life and functional status. $\mathrm{OR}=$ odds ratio; $\mathrm{CI}=$ confidence interval; $\mathrm{RPH}=$ restoration public housing.

who possessed fitness equipment. In the analysis, physical activity level was dichotomized owing to its deviation from normality. We additionally performed multiple regression analysis with the PAQ-EJ score as a continuous dependent variable.
Since these analyses revealed similar associations to those obtained from the logistic regression analysis (Supplementary Tables 1-3 [available online]), the main results in this study could be considered robust. 
The median physical activity level of 43.1 MET hr/week was remarkably low compared with the results of other studies on older Japanese individuals (79.3 $\pm 74.7 \mathrm{MET}$ hr/week; Yasunaga et al., 2007). Yoshii, Saito, Kikuchi, Ueno, and Sato (2014) described anxieties over radioactivity in women who were or became mothers and identified concerns about outdoor safety. This anxiety regarding overexposure to radiation during outdoor activities is also present in older men and women. This could have been a reason for limited physical activity in the participants of this study. As we did not measure participants' predisaster physical activity levels, it can only be assumed that this low physical activity level was a result of postdisaster lifestyle changes, with the fear of radiation exposure serving as a barrier to going outside.

The only environmental factor significantly associated with physical activity level was the presence of home fitness equipment. This result was consistent with two previous studies (Sallis, Johnson, Calfas, Caparosa, \& Nichols, 1997; Sallis et al., 2006). This finding can encourage increased physical activity in older adults, as owning exercise equipment is relatively independent of the objective environment. However, as per the stratified analysis, this association was observed only in the non-RPH group. This could have been because of the lack of appropriate areas to exercise using some equipment within the complex.

The results of this study showed that the role of poor scenery is amplified by residing in RPH. According to the stratified analysis, less enjoyable scenery was associated with physical activity only in the RPH group. In previous studies, the association between scenery and physical activity has been inconclusive. One study suggested that aesthetic attributes were associated with walking for a particular purpose (Owen, Humpel, Leslie, Bauman, \& Sallis, 2004), whereas another showed no correlation between these factors (Van Cauwenberg et al., 2011). Furthermore, a study reported that improvement of green space, representing aesthetics, was associated with being active (Jongeneel-Grimen, Droomers, van Oers, Stronks, \& Kunst, 2014). RPH residents experience a dramatic change of circumstance because of the relocation; thus, their perception of scenery seemed strongly associated with physical activity. As another possible factor, a previous study examining variation in neighborhood vegetation and physical activity in older men suggested that the association varied in participants with poor lower extremity function (Gong, Gallacher, Palmer, \& Fone, 2014). In this context, Ishii et al. (2015) reported that balance (lower extremity function) was impaired in temporary housing residents following the GEJE. In this study, RPH residents were more likely to have poor lower extremity function and be sensitive to an aesthetic factor (with fewer obstacles) to engage in more physical activity.

In this study, perceived environment factors were not significantly associated with physical activity. A previous study suggested that access to sports facilities was associated with physical activity; therefore, increased sports facility accessibility should be considered for promoting physical activity (Lee et al., 2016). Another study assessed recreational facility density as a measure of accessibility and found that it especially affected older individuals' physical activity (Ranchod, Diez Roux, Evenson, Sanchez, \& Moore, 2014). However, the cities where this study was conducted were not urban districts, so car use rates were higher than in metropolitan areas, such as Tokyo (Ministry of Land, Infrastructure, Transport and Tourism, 2017). Therefore, it is possible that the participants in this study traveled by car in many cases, resulting in low accessibility of goods on the physical activity level.

Previous findings regarding the association between neighborhood safety and physical activity are inconsistent. Tsunoda et al.
(2012) suggested that good traffic safety and aesthetics were positively associated with high levels of walking in older Japanese adults. By contrast, Inoue et al. (2009) reported that safety was not associated with physical activity, and Shibata et al. (2015) suggested that perceiving local traffic as a deterrent, instead of feeling safe walking in surrounding areas, was associated with physical activity. In this study, neighborhood safety was assessed using multiple factors, including lighting, sidewalk, and traffic volumes, which is perhaps why we were unable to identify the factor with the strongest association with physical activity.

Regarding the frequency of observing others exercising, its association with physical activity has been relatively consistently recognized in other studies (Giles-Corti, Timperio, Bull, \& Pikora, 2005; Trost, Owen, Bauman, Sallis, \& Brown, 2002). In Fukushima Prefecture, separation from family or/and community following the disaster had a psychological impact on locals (Maeda \& Oe, 2015), which resulted in weakened resilience within the community. In this situation, participants might have felt less motivated to engage in more physical activity even if they found that their neighbors were active.

Thus, some types of perceived environments were found not to be associated with physical activity. Postdisaster situations might attenuate the effect of environmental factors as accelerators of physical activity level. Although this study was conducted 7 years after the disaster, continuous consideration of the postdisaster situation and ways of transportation is necessary to make participants actively utilize the benefits of the perceived environment.

Based on the above discussion, we found that association with physical activity varied among various types of perceived environment, and the aspects of perceived environment that were associated with physical activity varied according to the experience of evacuation. To facilitate increased physical activity in those who experienced evacuation because of the GEJE, emphasis should be placed on pleasant surroundings. However, the development of city designs that incorporate attractive facilities encouraging physical activity is less important than recovering essential infrastructure or improving medical facility capacity following disasters. In addition, RPH residents had no say in their surrounding environment. As a countermeasure, providing information on neighboring places with scenic beauty may help RPH residents engage in more exercise. Regarding home fitness equipment, contrary to non$\mathrm{RPH}$ residents, there was no association in RPH residents. Therefore, for RPH residents, the allocation of specific exercise areas is necessary for the adequate utilization of the equipment provided; in a previous study, a farming program for improving evacuees' health was effective (Takahashi et al., 2015). Furthermore, it is interesting to note that the total score for perceived environment was associated with physical activity in RPH residents. Therefore, improving some other factors of perceived environment may also be beneficial for increasing physical activity levels in RPH residents.

There are several limitations to be considered. First, given the nature of cross-sectional studies, causal relationships between physical activity and perceived environment or other covariates could not be established. Second, participants' physical activity levels were assessed using a self-report questionnaire, which may be subject to recall bias as well as failing to provide objective measurements, as would be possible with devices such as accelerometers (Murphy, 2009). While subjective measurements were considered more feasible, they might have affected the accuracy of the data. Third, self-efficacy regarding physical activity was not assessed, so we could not adjust for this factor, although it has 
previously been associated with physical activity (Oka \& Shibata, 2012). Fourth, the experience of disaster, or the perception of radiation and its health risk, which may have affected participants' physical activity, remained unclear. Fifth, owing to the small number of participants, the results of the stratified analysis with all covariates should be interpreted with caution. Finally, owing to the low response rate, the sample may not necessarily be representative of all older adults residing in RPH and non-RPH in Fukushima Prefecture following the GEJE, which could affect the generalizability of the results.

Despite the abovementioned limitations, this study clarified the characteristics of perceived environment and physical activity as well as the association between them according to the experience of evacuation. Future studies should employ longitudinal designs to more fully examine the effect of perceived environment on physical activity and investigate ways to implement these findings in disaster-affected communities and individuals.

\section{Conclusions}

The association of aspects of perceived environment with physical activity levels in older citizens in Fukushima Prefecture following the GEJE varied according to whether they resided in RPH or not. An interaction effect of residence and enjoyable scenery on physical activity was observed. Among perceived environment measures, enjoyable scenery was significantly associated with physical activity in RPH residents. The association between physical activity and the summed score representing overall perceived environment was borderline significant in RPH residents. Possessing fitness equipment was associated with physical activity in non-RPH residents.

\section{Acknowledgments}

The authors would like to thank the participants of this study. This research was funded by KAKENHI, Japan Society for the Promotion of Science (JSPS), as a grant-in-aid for early career scientists, grant number $18 \mathrm{~K} 17385$. The sponsor did not play any role in study design, methods, recruitment, data collection, analysis, or preparation of the paper.

\section{References}

Caspersen, C.J., Powell, K.E., \& Christenson, G.M. (1985). Physical activity, exercise, and physical performance: Definitions and distinctions for health-related research. Public Health Reports, 100(2), 126131. PubMed ID: 3920711

Chang, H.C., Liang, J., Hsu, H.C., Lin, S.K., Chang, T.H., \& Liu, S.H. (2019). Regular exercise and the trajectory of health-related quality of life among Taiwanese adults: A cohort study analysis 2006-2014. BMC Public Health, 19(1), 1352. PubMed ID: 31646989 doi:10. 1186/s12889-019-7662-8

Fujiwara, T., Kondo, K., Shirai, K., Suzuki, K., \& Kawachi, I. (2014). Associations of childhood socioeconomic status and adulthood height with functional limitations among Japanese older people: Results from the JAGES 2010 project. The Journals of Gerontology, Series A: Biological Sciences \& Medical Sciences, 69(7), 852-859. PubMed ID: 24285745 doi:10.1093/gerona/glt189

Giles-Corti, B., Timperio, A., Bull, F., \& Pikora, T. (2005). Understanding physical activity environmental correlates: Increased specificity for ecological models. Exercise and Sport Sciences Reviews, 33(4), 175181. PubMed ID: 16239834 doi:10.1097/00003677-20051000000005
Glanz, K., Rimer, B.K., \& Viswanath, K. (Eds.). (2015). Health behavior: Theory, research, and practice (5th ed.). San Francisco, CA: JosseyBass.

Gong, Y., Gallacher, J., Palmer, S., \& Fone, D. (2014). Neighbourhood green space, physical function and participation in physical activities among elderly men: The Caerphilly prospective study. The International Journal of Behavioral Nutrition and Physical Activity, 11(1), 40. PubMed ID: 24646136 doi:10.1186/1479-5868-11-40

Hasegawa, A., Tanigawa, K., Ohtsuru, A., Yabe, H., Maeda, M., Shigemura, J., . . Chhem, R.K. (2015). Health effects of radiation and other health problems in the aftermath of nuclear accidents, with an emphasis on Fukushima. The Lancet, 386(9992), 479-488. doi:10.1016/S01406736(15)61106-0

Hurst, N.P., Ruta, D.A., \& Kind, P. (1998). Comparison of the MOS short form-12 (SF12) health status questionnaire with the SF36 in patients with rheumatoid arthritis. Rheumatology, 37(8), 862-869. doi:10. 1093/rheumatology/37.8.862

Inoue, S., Murase, N., Shimomitsu, T., Ohya, Y., Odagiri, Y., Takamiya, T., ... Sallis, J.F. (2009). Association of physical activity and neighborhood environment among Japanese adults. Preventive Medicine, 48(4), 321-325. PubMed ID: 19463488 doi:10.1016/j.ypmed. 2009.01.014

Ishii, T., Ochi, S., Tsubokura, M., Kato, S., Tetsuda, T., Kato, J., ... Tachiya, H. (2015). Physical performance deterioration of temporary housing residents after the Great East Japan Earthquake. Preventive Medicine Reports, 2, 916-919. PubMed ID: 26844168 doi:10.1016/j. pmedr.2015.10.009

Jongeneel-Grimen, B., Droomers, M., van Oers, H.A.M., Stronks, K., \& Kunst, A.E. (2014). The relationship between physical activity and the living environment: A multi-level analyses focusing on changes over time in environmental factors. Health \& Place, 26, 149-160. PubMed ID: 24448404 doi:10.1016/j.healthplace.2013.12.003

Koyano, W., Shibata, H., Nakazato, K., Haga, H., \& Suyama, Y. (1991). Measurement of competence: Reliability and validity of the TMIG Index of Competence. Archives of Gerontology and Geriatrics, 13(2), 103-116. PubMed ID: 15374421 doi:10.1016/0167-4943(91)90053-S

Lee, I.M., Shiroma, E.J., Lobelo, F., Puska, P., Blair, S.N., \& Katzmarzyk, P. (2012). Effect of physical inactivity on major non-communicable diseases worldwide: An analysis of burden of disease and life expectancy. The Lancet, 380(9838), 219-229. doi:10.1016/S01406736(12)61031-9

Lee, S.A., Ju, Y.J., Lee, J.E., Hyun, I.S., Nam, J.Y., Han, K.T., \& Park, E.C. (2016). The relationship between sports facility accessibility and physical activity among Korean adults. BMC Public Health, 16(1), 893. PubMed ID: 27565430 doi:10.1186/s12889-016-3574-z

Maeda, M., \& Oe, M. (2015). The Great East Japan Earthquake: Tsunami and nuclear disaster. In K.E. Cherry (Ed.), Traumatic stress and longterm recovery: Coping with disasters and other negative life events (pp. 71-90). New York, NY: Springer.

McPhee, J.S., French, D.P., Jackson, D., Nazroo, J., Pendleton, N., \& Degens, H. (2016). Physical activity in older age: Perspectives for healthy ageing and frailty. Biogerontology, 17(3), 567-580. PubMed ID: 26936444 doi:10.1007/s10522-016-9641-0

Minardi, V., Gigantesco, A., Mancini, C., Quarchioni, E., D’Argenio, P., \& Cofini, V. (2016). Behavioural risk factors in L'Aquila (Central Italy) 3-5 years after the 2009 earthquake. Epidemiologia e Prevenzione, 40(2, Suppl. 1), 34-41. PubMed ID: 27291206 doi:10. 19191/EP16.2S1.P034.045

Ministry of Health, Labour and Welfare. (2013). Active guide: Japanese official physical activity guidelines for health promotion. Retrieved from https://www.nibiohn.go.jp/eiken/english/research/pdf/active_ guide2013.pdf 
Ministry of Land, Infrastructure, Transport and Tourism. (2017) Toshiniokeru Hito No Ugoki To Sono Henka. Retrieved from http://www. mlit.go.jp/common/001223976.pdf

Moriyama, N., Iwasa, H., Tsubokura, M., Kuroda, Y., \& Yasamura, S. (2019). Living in the restoration public housing after the Great East Japan Earthquake correlates with lower subjective well-being of older adults. International Journal of Environmental Research and Public Health, 16(15), 2696. doi:10.3390/ijerph16152696

Moriyama, N., Urabe, Y., Onoda, S., Maeda, N., \& Oikawa, T. (2017). Effect of residence in temporary housing after the Great East Japan Earthquake on the physical activity and quality of life of older survivors. Disaster Medicine and Public Health Preparedness, 11(6), 701-710. PubMed ID: 28625213 doi:10.1017/dmp.2017.19

Murakami, H., Tripette, J., Kawakami, R., \& Miyachi, M. (2015). "Add 10 min for your health": The new Japanese recommendation for physical activity based on dose-response analysis. Journal of the American College of Cardiology, 65(11), 1153-1154. PubMed ID: 25790890 doi:10.1016/j.jacc.2014.10.080

Murakami, H., Yoshimura, E., Ishikawa-Takata, K., Nishi, N., TsuboyamaKasaoka, N., Yokoyama, Y., ... Miyachi, M. (2014). The longitudinal change in physical activity among Great East Japan Earthquake victims living in temporary housing. Nippon Koshu Eisei Zasshi, 61, 86-92. PubMed ID: 24739878 doi:10.11236/jph.61.2_86

Murphy, S.L. (2009). Review of physical activity measurement using accelerometers in older adults: Considerations for research design and conduct. Preventive Medicine, 48(2), 108-114. PubMed ID: 19111780 doi:10.1016/j.ypmed.2008.12.001

Ochi, S., Tsubokura, M., Kato, S., Iwamoto, S., Ogata, S., Morita, T., ... Saito, Y. (2016). Hospital staff shortage after the 2011 triple disaster in Fukushima, Japan-An earthquake, tsunamis, and nuclear power plant accident: A case of the Soso district. PLoS One, 11(10), e0164952. PubMed ID: 27788170 doi:10.1371/journal.pone.0164952

Ohira, T., Nakano, H., Nagai, M., Yumiya, Y., Zhang, W., Uemura, M., ... Hashimoto, S. (2017). Changes in cardiovascular risk factors after the Great East Japan Earthquake. Asia-Pacific Journal of Public Health, 29(Suppl. 2), 47S-55S. PubMed ID: 28330394 doi:10.1177/ 1010539517695436

Oka, K., \& Shibata, A. (2012). Determinants of meeting the public health recommendations for physical activity among community-dwelling elderly Japanese. Current Aging Science, 5(1), 58-65. PubMed ID: 21762088 doi:10.2174/1874609811205010058

Oka, K., Togo, F., \& Aoyagi, Y. (2004). Koureisya ni okeru kyakkanteki ni sokutei sareta shintaikatsudoushihyou no kiteiyouin wo kaimei suru tameno maemuki kenkyuu [A prospective study on determinants of objectively measured physical activity among elderly Japanese]. Descente Sports Science, 25, 72-81.

Owen, N., Humpel, N., Leslie, E., Bauman, A., \& Sallis, J.F. (2004). Understanding environmental influences on walking: Review and research agenda. American Journal of Preventive Medicine, 27(1), 67-76. PubMed ID: 15212778 doi:10.1016/j.amepre.2004.03.006

Ranchod, Y.K., Diez Roux, A.V., Evenson, K.R., Sanchez, B.N., \& Moore, K. (2014). Longitudinal associations between neighborhood recreational facilities and change in recreational physical activity in the multi-ethnic study of atherosclerosis, 2000-2007. American Journal of Epidemiology, 179(3), 335-343. PubMed ID: 24227016 doi:10.1093/aje/kwt263

Sallis, J.F., Cervero, R.B., Ascher, W., Henderson, K.A., Kraft, M.K., \& Kerr, J. (2006). An ecological approach to creating active living communities. Annual Review of Public Health, 27(1), 297-322. PubMed ID: 16533119 doi:10.1146/annurev.publhealth.27.021405.102100

Sallis, J.F., Johnson, M.F., Calfas, K.J., Caparosa, S., \& Nichols, J.F. (1997). Assessing perceived physical environmental variables that may influence physical activity. Research Quarterly for Exercise and Sport, 68(4), 345-351. PubMed ID: 9421846 doi:10.1080/02701367. 1997.10608015

Sallis, J.F., \& Owen, N. (1999). Physical activity and behavioral medicine. Thousand Oaks, CA: SAGE Publications.

Sasaki, Y., Aida, J., Tsuji, T., Koyama, S., Tsuboya, T., Saito, T., ... Kawachi, I. (2019). Pre-disaster social support is protective for onset of post-disaster depression: Prospective study from the Great East Japan Earthquake \& Tsunami. Scientific Reports, 9(1), 19427. PubMed ID: 31857658 doi:10.1038/s41598-019-55953-7

Shakespeare-Finch, J., \& Obst, P.L. (2011). The development of the 2-Way Social Support Scale: A measure of giving and receiving emotional and instrumental support. Journal of Personality Assessment, 93(5), 483-490. PubMed ID: 21859288 doi:10.1080/00223891. 2011.594124

Shibata, A., Oka, K., Harada, K., Nakamura, Y., \& Muraoka, I. (2009). Psychological, social, and environmental factors to meeting physical activity recommendations among Japanese adults. The International Journal of Behavioral Nutrition and Physical Activity, 6(1), 60. PubMed ID: 19715568 doi:10.1186/1479-5868-6-60

Shibata, A., Oka, K., Sugiyama, T., Ding, D., Salmon, J., Dunstan, D.W., \& Owen, N. (2015). Perceived neighbourhood environmental attributes and prospective changes in TV viewing time among older Australian adults. International Journal of Behavioral Nutrition and Physical Activity, 12(1), 50. PubMed ID: 25889061 doi:10.1186/ s12966-015-0208-2

Shimizu, H. (2016). An introduction to the statistical free software HAD: Suggestions to improve teaching, learning and practice data analysis. Journal of Media, Information and Communication, 1, 59-73.

Stewart, A.L., Mills, K.M., King, A.C., Haskell, W.L., Gillis, D., \& Pitter, P.L. (2001). CHAMPS Physical Activity Questionnaire for Older Adults: Outcomes for interventions. Medicine and Science in Sports and Exercise, 33(7), 1126-1141. PubMed ID: 11445760 doi:10. 1097/00005768-200107000-00010

Takahashi, S., Ishiki, M., Kondo, N., Ishiki, A., Toriyama, T., Takahashi, S., \& Tabata, K. (2015). Health effects of a farming program to foster community social capital of a temporary housing complex of the 2011 Great East Japan Earthquake. Disaster Medicine and Public Health Preparedness, 9(2), 103-110. PubMed ID: 25682770 doi:10.1017/ dmp.2015.6

Trost, S.G., Owen, N., Bauman, A.E., Sallis, J.F., \& Brown, W. (2002). Correlates of adults' participation in physical activity: Review and update. Medicine and Science in Sports and Exercise, 34(12), 19962001. PubMed ID: 12471307 doi:10.1097/00005768-200212000-00020

Tsunoda, K., Tsuji, T., Kitano, N., Mitsuishi, Y., Yoon, J.Y., Yoon, J., \& Okura, T. (2012). Associations of physical activity with neighborhood environments and transportation modes in older Japanese adults. Preventive Medicine, 55(2), 113-118. PubMed ID: 22634110 doi:10. 1016/j.ypmed.2012.05.013

Van Cauwenberg, J., De Bourdeaudhuij, I., De Meester, F., Van Dyck, D., Salmon, J., Clarys, P., \& Deforche, B. (2011). Relationship between the physical environment and physical activity in older adults: A systematic review. Health \& Place, 17(2), 458-469. PubMed ID: 21257333 doi:10.1016/j.healthplace.2010.11.010

von Elm, E., Altman, D.G., Egger, M., Pocock, S.J., Gøtzsche, P.C., \& Vandenbroucke, J.P. (2007). The strengthening the reporting of observational studies in epidemiology (STROBE) statement: Guidelines for reporting observational studies. PLoS Medicine, 4(10), e296. PubMed ID: 17941714 doi:10.1371/journal.pmed.0040296

World Health Organization. (2009). Global health risks: Mortality and burden of disease attributable to selected major risks. Retrieved from 
https://www.who.int/healthinfo/global_burden_disease/GlobalHealth Risks_report_full.pdf

Yasumura, S., Goto, A., Yamazaki, S., \& Reich, M.R. (2013). Excess mortality among relocated institutionalized elderly after the Fukushima nuclear disaster. Public Health, 127(2), 186-188. PubMed ID: 23158829 doi:10.1016/j.puhe.2012.10.019

Yasunaga, A., Park, H., Watanabe, E., Togo, F., Park, S., Shephard, R.J., \& Aoyagi, Y. (2007). Development and evaluation of the physical activity questionnaire for elderly Japanese: The Nakanojo Study. Journal of Aging and Physical Activity, 15(4), 398-411. PubMed ID: 18048944 doi:10.1123/japa.15.4.398

Yoshii, H., Saito, H., Kikuchi, S., Ueno, T., \& Sato, K. (2014). Report on maternal anxiety 16 months after the great East Japan earthquake disaster: Anxiety over radioactivity. Global Journal of Health Science, 6(6), 1-10. PubMed ID: 25363115 doi:10.5539/ gjhs.v6n6p1 